ICAASET-2021, 20-21 May, 2021, K.R. Mangalam University, Gurugram

International Journal of Technical Research \& Science (Special Issue) ISSN No.:2454-2024 (online)

\title{
A COMPREHENSIVE REVIEW ON WATER TREATMENT TECHNIQUES
}

\author{
Rashmi Kakkar, Dilraj Preet Kaur, Seema Raj
}

E-Mail Id: rashmikakkar02@gmail.com, dilraj.k@krmangalam.edu.in, seema.raj@krmangalam.edu.in School of Basic and Applied Sciences, K.R. Mangalam University, Gurugram, Haryana

Abstract-With the growing population across the world, there is a call for the availability of freshwater to meet our necessities. There is an increase in water scarcity from $14 \%$ of the global population in the 1900 s to $58 \%$ in the 2000s. Though we have nearly 70 percent of the earth's surface covered with water, still only 0.5 percent of total water is available for human consumption because almost $97 \%$ of water is sea water which requires desalination and water purification to make it apt for drinking purposes. Over many years our researchers have been working on various techniques such as Multistage distillation, Reverse Osmosis (RO), Membrane Distillation (MD), Electrodialysis (ED), Nanofiltration (NF), Ultrafiltration (UF), Forward Osmosis (FO), Solar desalination,etc. This paper reviews the various processes (advantages \& disadvantages) and their commercialization.

\section{INTRODUCTION}

It is a challenge for human life, plant kingdom,and animal life to meet the demand for freshwater which is only $2.5 \%$ available on the earth's surface because the rest of available water is in the form of ice caps, groundwater $\&$ glaciers only which leads to a very very small percentage of surface freshwater [1] Almost $1 / 3^{\text {rd }}$ of world's population is bearing the stress of water scarcity and with the increasing industrialization and growing population, it is expected an increase in this percentage [2]. Mainly we call it a water shortage, if the water capital (water level per year per person) falls below 1000m3 [3]. As $97 \%$ of water available is from the sea only so the best technique is to desalinate the seawater with various techniques. This is also called Desalination (a process of removing dissolved salts and minerals from the saline water). It depends on TDS (Total dissolved solids) whether the saline water is brackish or it is a seawater. For brackish water (TDS 10,000ppm) and for seawater (TDS $45,000 \mathrm{ppm}$ ) [4]. But the allowed limit of salinity in potable water is of range 500 to $1000 \mathrm{ppm}$ [5]. With the depleting fossil fuels it is an alarming situation to find out other sources which are available i.e. renewable sources on earth and make them useful for the desalination process. This review paper also helps researchers to compare various techniques and choose the best one for the desalinating process.

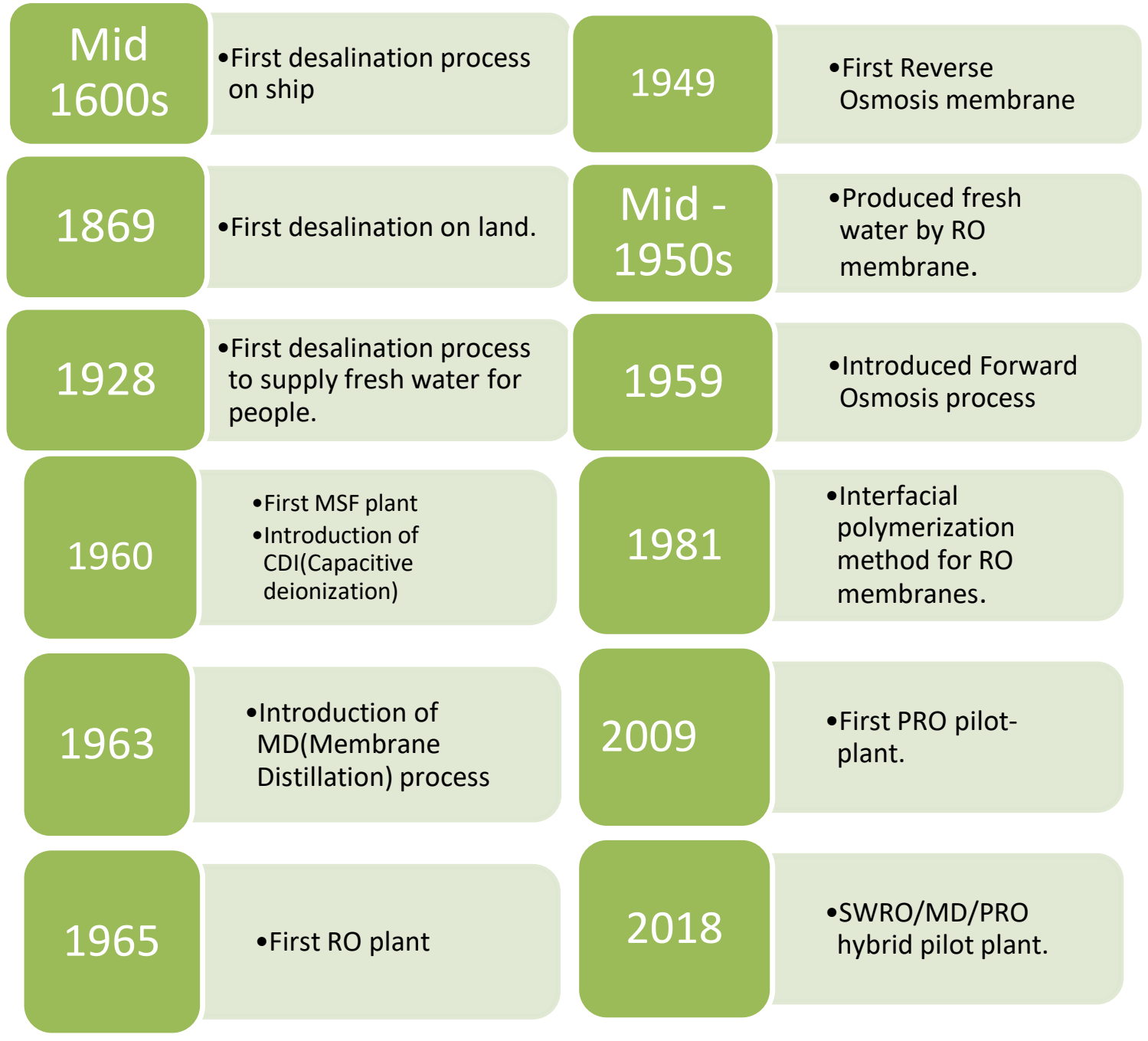


ICAASET-2021, 20-21 May, 2021, K.R. Mangalam University, Gurugram

International Journal of Technical Research \& Science (Special Issue) ISSN No.:2454-2024 (online)

\section{VARIOUS ADVANCED WATER PURIFICATION TECHNIQUES}

The two distillation technologies mainly used for world desalination are based on thermal energy and membrane technology. Most of the Middle East countries make use of processes such as MSF, MED, etc. which are based on thermal energy and while the developed countries such as the USA are commercially using membrane-based processes such as RO (Reverse Osmosis), MD (Membrane Distillation), ED (Electrodialysis), etc. [6]

\section{DIFFERENT TYPES OF PURIFICATION PROCESSES}

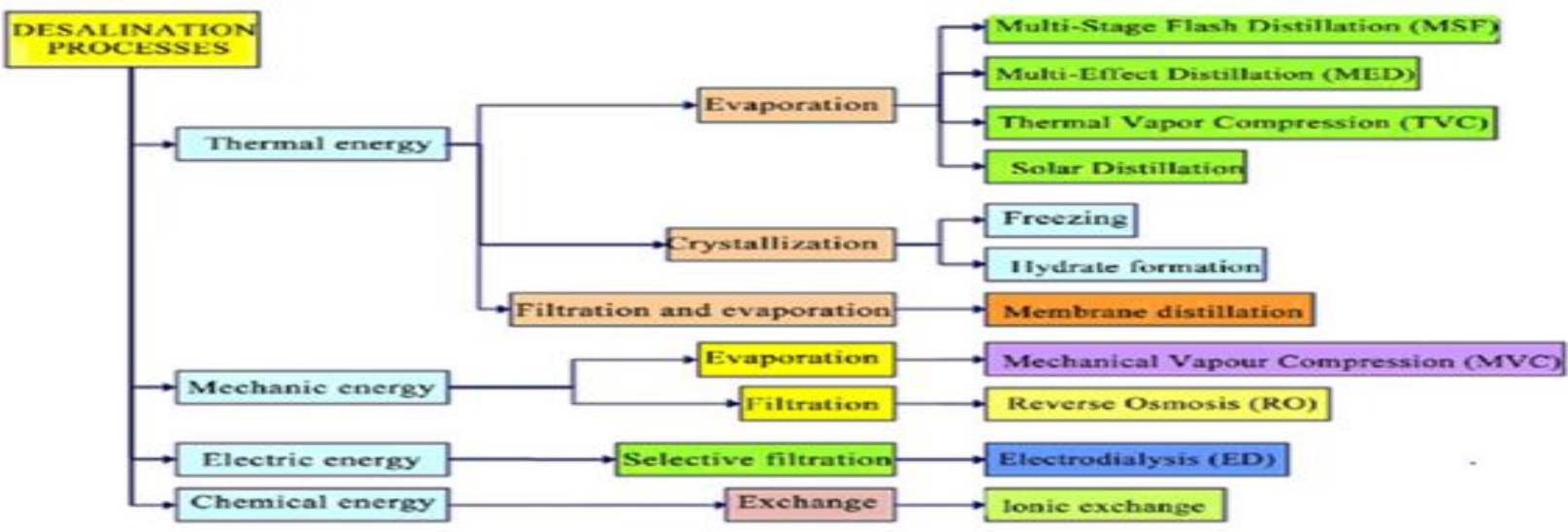

\section{MULTISTAGE FLASH DISTILLATION}

It is a process that sends the saline feed water through various chambers where the water is heated and compressed to high pressure and temperature. While passing through these chambers, there is a reduction in pressure due to which water starts boiling rapidly and thus the vapour formed which is freshwater is then condensed and collected [6]. It's around the beginning of the 21st century when the MSF (Multistage Flash Desalination) technique was able to hold more than $50 \%$ of the market of desalination industry. Though it has many advantages such as good production, ease to operate and construct but still, there was a need to reduce its production cost. For this, the modified (MSF-M) has been proposed which involves the addition of a mixing tank for feed stream and the removal heat rejection section. The analysis of this modified (MSF-M) process shows a remarkable increase in the thermal performance ratio by a factor of 2-3 over conventional MSF [7].

\section{THERMAL VAPOUR COMPRESSION}

This method refers to the evaporation of sea or saline water which is obtained by delivering heat of compressed vapour. Besides fresh water, desalination also produces brine (high greenhouse gasses. To solve both issues, a study proposed a solar multi-effect distillation/thermal vapour compression (SEMD-TVC) hybrid system. The basic aim is to desalinate brine, to recover freshwater of high purity. The evaluation of this hybrid process has been done by the techno-economic model which discus this process in two cases: There is an increase in freshwater production capacity (from 10 cubic metres per day to 50 cubic metres per day). Plant lifetime increases from 20 to 35 years [8]. Performance Evaluation of small size TVC desalination plant has also been done which consist of two TVC units each of 375 cubic metre/d capacity. Few problems have been observed which were affecting the problems of plant such as the steam boiler and fouling in the condenser, also the imbalance steam flow leading to imbalance temperature of the boiler. But even after all these limitations, the plant proves to work satisfactorily through 15 months. Overall performance was found to be 70 to $80 \%$. To eradicate operational performance in winters we need a heat exchanger which may be cost-effective also (9). A study of steam parameters on the performance of a TVC-MED (Mutieffect desalination with thermal vapour compressor) plant was developed and model validity was examined. Also for different steam pressures and temperatures the performance was evaluated. For increasing gain output ratio the enhancement of motor pressure is required. Also, energy consumption can be reduced by increasing the suction steam temperature (10).

\section{SOLAR DESALINATION}

Solar Desalination, as the name suggests utilizes solar energy to desalinate or to remove the impurities found within water. Literature reviews also analyse the need for research into other renewable resources for water desalination. Though Reverse osmosis accounts for $52 \%$ of global desalination. But $22 \%$ of the desalination processes are thermally driven. Economic studies of thermal and membrane desalination showed that in comparison to reverse osmosis, thermal desalination had a lower average cost [11]. An experimental study of the performance of pyramid-shaped solar still was also carried out which shows a comparison between the free convection solar still with the pyramid-shaped solar and observed that the daily yield was increased up to $25 \%$ [12]. The study also showed a solar desalination system that combined solar thermal collectors, heat storage tanks and a spray assisted with low temperature and the system is evaluated for energy efficiency and productivity under conditions of Makkah, Saudi Arabia. Results concluded that the water cost of the proposed desalination system is less than the solar energy driven thermal desalination system. It can provide an 
interrupted water supply of $20 \mathrm{~kg} /$ day per sq. metre [13]. Over the past 40 years, desalination technology has been extensively developing. The study of hybrid systems such as solar/MSF, solar/RO, solar/MED has been analyzed theoretically. It was concluded theoretically only (no experimental proof as such) that these hybrid systems can be competitive with other existing techniques for small scale desalination up to 10 cubic meters per day to provide drinking water in remote areas which have less accessibility to freshwater [14]. A paper also reports the cost-analysis for various active and passive solar stills. For this basically, two parameters were chosen: present capital cost \& annual yield. The conclusion drawn was as follows: Passive solar stills are proved to be better in comparison to active solar stills in terms of present capital cost and the one (passive single effect tubular type) which is made up with local materials shows the minimum cost per litre of $0.0074 \$ / 1$ whereas the other solar still has CPL of $0.1776 \$ / 1$. The passive solar stills are more recommendable due to economic factors [15]. Solar desalination is not an emerging or useful technology in Middle East countries but even in India (tropical country), it is seen to be an appropriate technology as India also receives plenty of sunshine. It receives about 5000 trillion KWh of solar energy in a year. Based on this report it comes to the following conclusions such as:

$>$ Solar energy is pollution-free as well as cost-free

$>$ The areas w/c are away from freshwater sources, the solar stills proved to be a good choice.

$>$ Also concluded that single sloped solar still is better than double solar because the former receive more radiation.

A $20 \%$ higher yield can be observed in the case of double condensing with multiple solar still.

$>$ A combination of greenhouses with solar stills is also feasible

For maximum annual yield, the angle of inclination should be 20 degrees in the flat-plate collector and 15 degrees in still glass cover inclination [16]. The economic \& environmental feasibility of solar desalination has also been reported by some researchers. For this a rank scores $(0<\mathrm{R}<1)$ have been calculated for various countries where the solar desalination technique is most applicable. Observations inferred that: For the landlocked countries it comes out with low scores $(\mathrm{R}<0.125)$. Also, the score is low for the countries which are near-polar region (eq. Russia, Canada etc.). For the Middle East countries where the solar desalination technique is appropriate the $\mathrm{R}>0.422$, is observed in about 30 nations. For 28 further countries such as China, India, Indonesia, Australia etc. it lies in b/w $0.273 \& 0.422$ [17].

\section{HYBRID ION EXCHANGE METHOD}

Though the ion exchange method is not used directly for desalination when it is hybridized with other methods, the results are remarkable. A study conducted a review on the coupling of ion exchange resin with reverse osmosis and ultrafiltration membrane, it was concluded that the efficiency has been improved and operational cost reduces along with the removal of trace pollutants in water. Authors also regarded this hybrid system as a standard boron removal technique [18]. Alharati achieved boron removal to a high level of $0.3 \mathrm{mg} / \mathrm{L}$ by combining ion-exchange pre-treatment with nanofiltration while treating natural groundwater [19]. An interesting result claimed by researchers states that the hybrid ion exchange and microfiltration system showed a reduction in surface watercolour to $0.05 \mathrm{mg} / \mathrm{L}$ on a platinum/cobalt state [20]. A report also exists which consists of two parts. In the first part, there is a one stage electro-dialysis process operating at a constant current mode. While in the second part, the saline water is desalinated by using a multistage electrodialysis program through which the salt concentration of a feeding solution is changing at every stage. The evaluation in terms of energy consumption, water recovery, membrane area is evaluated [21]. To show the improved desalting efficiency of MCDI (Membrane Capacitive deionization) an addition of ion-exchange membranes have been done in front of carbon nanotubes electrodes so that the selectively charged ions pass through the membrane and are absorbed by oppositely charges electrodes which help in improved salt removed efficiency. Results indicate that the CDI without membrane has average salt removal efficiency of about $60 \%$ whereas the one with membrane has good efficiency of $97 \%$ with initial conductivity of $110 \mathrm{~ms} / \mathrm{cm}$ and electrical voltage of $1.2 \mathrm{~V}$ [22]. The first plant in the world using combined technology of Ion-exchange and reverse osmosis was set up in May 2006, Israel. This combination helps in the reduction of overall operating cost as well as capital cost for removal of boron from desalinated seawater. This plant was fed with brackish water and the produced fresh water was consumed for human consumption and irrigation purpose [23].

\section{ELECTRODIALYSIS}

It is a membrane separation technique in which the ions pass through an ion-exchange membrane driven by an externally applied electric field. A.H. Galama et al. studied the desalination of seawater with the help of electrodialysis and also analyses the importance of quantification of energy losses. They presented a hybrid system of ED (Electrodialysis) \& SWRO (Seawater Reverse Osmosis) as an alternative method for desalination. Experiments have been performed with a recycling electrodialysis. From this, they concluded that the major loss of energy is caused by the stacking of membranes. It was observed that with the low current density, this hybrid system of ED with SWRO does not lower energy consumption. Also at low applied current density, the cost of operation of ED is less than SWRO [24]. The bipolar membrane (BPM) electrodialysis process has also been investigated for its efficiency using TDS and conductivity changes in the acid and base compartments [25]. Reports also discussed the laboratory set-up of ED. The study was done on the analysis of Taguchi data which analysis the effect of various concentrations such as 10000, 20000, $40000 \mathrm{ppm}$ also for different temperatures such as $25^{\circ} \mathrm{C}, 40^{\circ} \mathrm{C}$ and $55^{\circ} \mathrm{C}$ and with different flow rates such as $0.07,0.13,0.22 \mathrm{ml} / \mathrm{s}$ for different voltages 5 , 7, $9 \mathrm{~V}$ for the evaluation of this ED setup was done. Results conclude that High Voltage and Temp. with less 
concentration And flow rates were recommended for better performance of ED cells [26]. The water generated in the oil and gas industry cannot be reversed because of its salt content. But this PFPW (polymer flooding produced water) can be desalinated by using the ED technique. For this, experimental work was conducted which involves the desalting of two types of PFPW solutions (one is Brackish PFPW and the other is seawater PFPW) at two different temperatures. It was found that the presence of polymer did not effectively influence the energy consumption in seawater cases but desalts brackish water at $20{ }^{\circ} \mathrm{C}$ [27]. Few assessments also indicate that ED can be most effective for the production of potable water whose TDS (total dissolved salt) concentrations lies between 1000 to $10000 \mathrm{ppm}$. But the cost of SWED set up is more expensive in comparison with RO setups [28].

\section{BY USING FLY ASH}

Fly Ash produced in the combustion of pulverized coal and is transported from the combustion chamber by exhaust gases. Mohammed Yaseen et al. studied a low-cost water filter that is designed for a 7-litre capacity. The main aim was to use the adsorption technique for the removal of fluorides from water. Few other parameters have also been investigated such as TDS (total dissolved oxygen), alkalinity hardness and $\mathrm{pH}$. Results concluded a comparison between fly ash and activated carbon. Except for removing hardness, the flash shows better result [29]. A study reported the successful preparation of polymeric membranes (based on flash) was done. And further, the microfiltration process was used for water treatment. Results show that polymerization is a promising sintering-free technology for the treatment of produced water. Results prove that these membranes are efficient in reducing total dissolved salts, hardness, turbidity etc. [30]. Researchers also reviewed the successes of fly-ash in removing various dyes, pesticides and pollutants from wastewater. The various unique characteristics such as high porosity, large specific surface area etc. make fly-ash suitable to use for the treatment of air and water pollution [31]. Paper also represents the modification in characteristics of fly ash such as the change in morphology, specific surface area, crystal structure. This modification was by 2 mercaptobenzothiazole (MBT) and sodium dodecyl sulphate $\mathrm{NaOH}$ solution. The amount of adsorbed ions by the modified fly ash was higher than that of unmodified fly ash [32]. Not only with the help of RO \& ionexchange method we can remove boron concentration present in water. But also with the help of coal and fly ash under controlled conditions such as pre-treatment, $\mathrm{pH}$, liquid/solid ratio etc. we can solve this serious issue. The reaction was proposed in this report which indicates the reaction of $\mathrm{Mg}$-rich seawater with Ca-rich fly ash which results in co-precipitation of magnesium hydroxide along with precipitation of Boron [33].

\section{MEMBRANE DISTILLATION}

A thermally driven separation in which only vapour molecules can transfer through a microporous hydrophobic membrane. To analyse the abilities of the MD (Membrane Distillation) technique to desalinate the raw water was investigated by performing experiments on a direct contact membrane distillation (DCMD) unit by using a flat sheet hydrophobic propylene membrane with low pore size. The results indicated that enhancement of permeate flux can be achieved by increasing feed Reynolds number and by increasing the temperature difference of transmembranes [34]. In a comparison of various inorganic membranes tested so far for water desalination, the zeolites membranes which are prepared by reducing calcination time by 14th shows a better result with high salt rejections and high flux. This leads to faster preparation of zeolites membranes with reduced energy consumption [35]. Atia represents a study on the investigation of effects of feed temperature, feed flow rates, air gap width etc. on the flux of an AGMD (air gap membrane distillation). Results concluded that with the increasing feed rate and feed temperature the permeate flux can be achieved [36]. The study reports the comparison of 3 PP \& one PE microporous hollow-fibre membranes used with VMD \& DCMD for desalination of seawater. The effect of feed temp \& feed flow was investigated. It was observed that with an increase of feed temp. \& feed flow in both DCMD \& VMD, the water flux can be increased. Also, the use of PE membranes in both the DCMD \& VMD process has proved to be more beneficial in comparison to PP membranes [37]. Among the various configurations of MD the VMD has received great attention in several applications of seawater desalination. For the investigation of VMD performance, the process is set up w/ch consists of a PTFE (hydrophobic microporous) membrane and a vacuum pump without the condenser for water recovery has been used and the effect of various parameters such as feed temp feed concentration, feed flow etc. Results show that this VMD performance could reach up to $99.99 \%$ of salt removal. Flux reaches up to 14.62 $\mathrm{kg} / \mathrm{m} 2 \mathrm{~h}$ at $333 \mathrm{k}$ bulk feed temp. and at permeate pressure of $1 / 5 \mathrm{k} \mathrm{Pa}$ with $541 / \mathrm{h}$ feed flow rate and 30,000 mg/l feed concentration. Also found that the issue of fouling can also be solved [38]. Comparisons of various single stage MD configurations have been investigated by making a comparison of gained output ratio across all configurations. Several conclusions have been concluded as follows: The AGMD has the greatest impact on GOR and the GOR of a single-stage VMD system is limited to less than 1 [39].

\section{NANO FILTRATION}

This is a recent membrane filtration process used most often with fresh groundwater as well as surface water, to soften and remove disinfection by-products. An earlier study by Mona Amin reports the existence of linear relation between total operation cost and the environmental impact of nanofiltration technique. The main objective of this paper was to illustrate the main applications of the NF process in water softening, wastewater treatment and desalination fields. But the problem of durability, Fouling, low flux are the main barriers in this achievement [40]. Another paper reviews the characteristics of NF (Nanofilteration) membranes which includes high permeation to monovalent ions, low permeation to divalent ions and higher flux than reverse osmosis. The 
ICAASET-2021, 20-21 May, 2021, K.R. Mangalam University, Gurugram

International Journal of Technical Research \& Science (Special Issue) ISSN No.:2454-2024 (online)

low costs, reliability and long life of NF membranes make it a more attractive technique. The future developments of NF use, involving 2D nanomaterials and metal dichalcogenides are also discussed [41]. With seven potential draw solutions, an investigation of laboratory-scale FO NF test cells has been done. Results conclude that FO-NF can be a feasible process for seawater desalination and also the water flux has reached up to $102 / \mathrm{MWh}$ for both FO \& NF process. Out of seven, for the four draw solutions, the solute rejections reached up to $97.9 \%$ [42].

\section{REVERSE OSMOSIS}

This uses the concept of osmosis pressure differences phenomena between pure water and saltwater to remove salts from water [43]. In this process, the feed stream is allowed to flow through a semipermeable membrane which separates the salt-rich and salt poor streams. When the pressure applied becomes higher than the osmotic pressure then salt is retained [44]. An analysis of RO Desalination plants with various water sources has also been done. Figure 1 gives an analysis of the same [45].

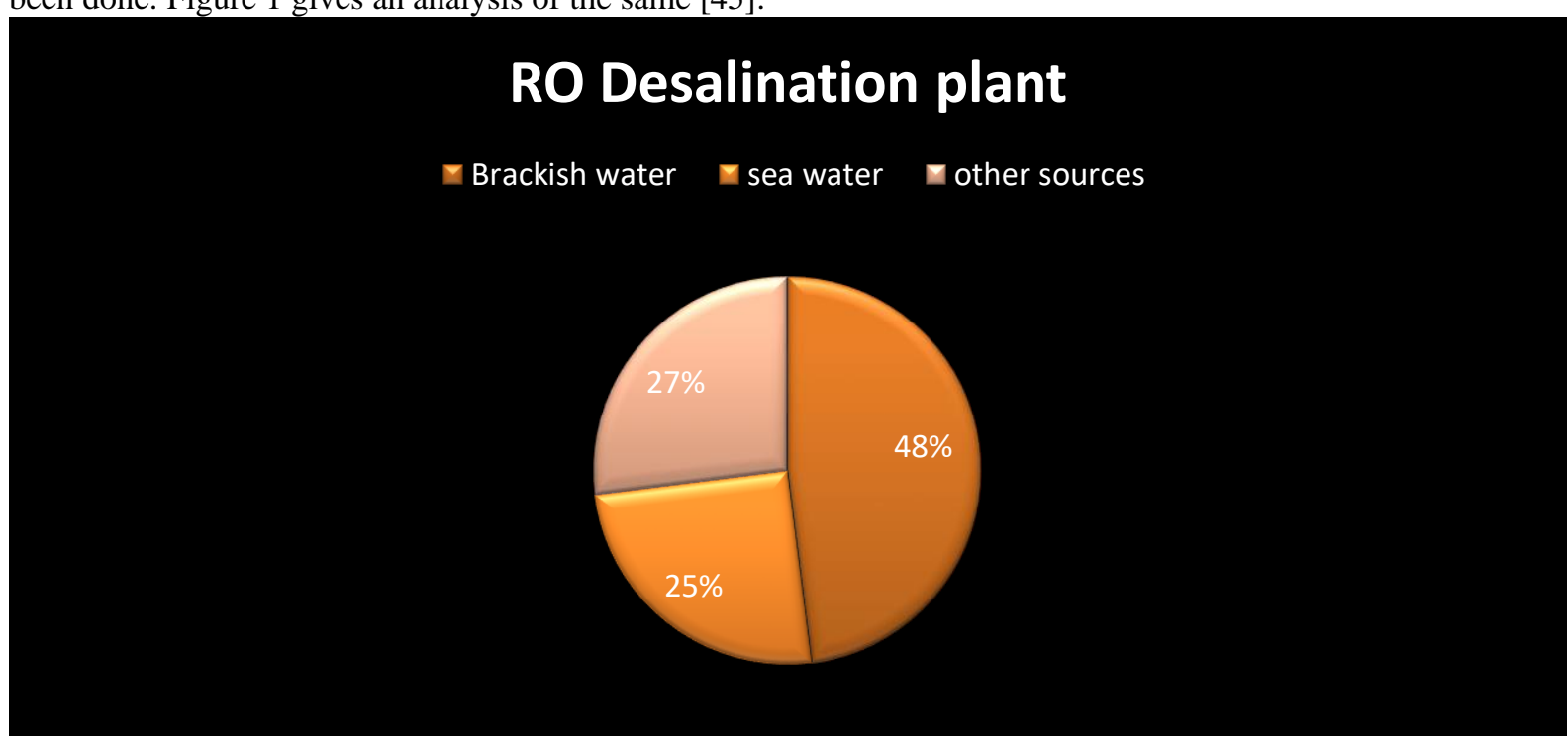

Fig. 11.1 RO desalination plant based on various feed water [45]

But the main limitations as far observed are less productivity and effects of rejected brines on our environment. To eradicate these issues there is a requirement of large energy consumption and scaling on membrane surface [46]. Also, reports show experimental observations of recovery rate \% of RO Desalination plants with MD Desalination plant with seawater and groundwater as feed source (figure 2) [47].

Table-11.1 Recovery of water in RO and MD plants [47]

\begin{tabular}{|l|l|l|l|}
\hline Feed water & RO plant & MD plant & Reference \\
\hline Sea water & 40.08 & 77 & $45(\mathrm{~A})$ \\
\hline Ground water & 90 & NA & 45 \\
& & & \\
\hline
\end{tabular}

\section{FORWARD OSMOSIS}

Another osmotic process uses a highly concentrated draw solution. To reach the equilibrium of chemical potential this draw solution will provide a gradient that provides the needed osmotic pressure. This unit provides simultaneous recovery of freshwater as well as regeneration of draw solution [48]. The FO process has several advantages over other techniques as it does not require external pressure which makes energy consumption lower compared to pressure-driven processes. Due to the use of osmotic pressure the fouling reversal has become easier. Choice of any draw solutions makes it more advantageous. Achieve osmotic pressure by RO for the highly saline feed require more energy in comparison FO technique [49-52]. Generally, reverse osmosis has proved to be highly efficient and applicable for seawater desalination over a large scale. But literature also reviews the comparison between $\mathrm{RO} \& \mathrm{FO}-\mathrm{RO}$ process with two different salts, $\mathrm{NaCl}$ and Magnesium chloride as draw solutions. It was concluded that the power consumption in the FO process was only $2 \%-4 \%$ of the total power consumed in the FO-RO process. Also, it has been observed that the lowest permeate TDS reached up to 0.65 mol of magnesium chloride in the FO-RO process [53]. Another paper reports the usage of cross-linked polyamide membranes to measure the boron permeabilities with the help of a computer program which makes the calculation easier. The results were compared with the data taken at the RO plant at Toray Industries, Ehime. Also by solving the transport equation it was found that a relation co-exists between salt \& boron concentration in permeate [54]. Recent studies have also been focussed on developments of RO TFC membranes for solving the membrane fouling problems as well as for developing great stability against chlorine attack. But the main concern with RO TFC membranes is their low boron removal rate. The SWRO (seawater reverse osmosis) desalination process with multi-stages membrane filtrations has proved to be better for complete boron removal but this turn out to be expensive [55].

DOI Number: https://doi.org/10.30780/specialissue-ICAASET021/015 


\section{DESALINATION ACROSS WORLD}

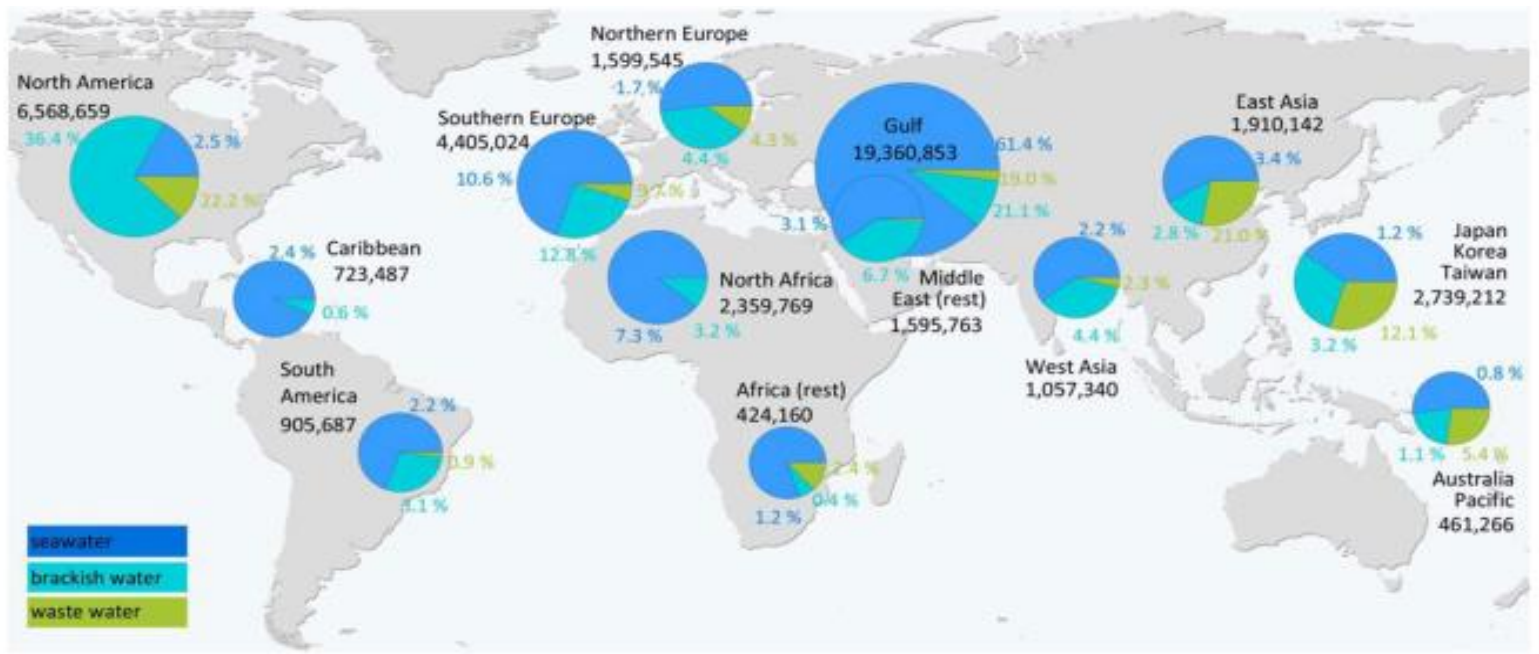

Fig. 13.1 International desalination capacity (m3/d, \%) [56]

For desalination, there are various water resources namely from sea water to waste water. Major contribution is through sea water only as compared to other resources. Usage of brackish water, underground salt water for feed has been growing since 2000 [57]. Figure 3 shows the changes in the shares of water resources from 2010 to 2011, this also indicates that major contribution is from sea water. Freshwater implies the water with a salinity of $100-500 \mathrm{ppm}$ but

hardly $3-5 \%$ of the world's water lies in this category (Reif and Alhalabi 2015010). Fig. 4 shows the percentage of water resources for the desalination process for 2010 (a) and 2011 (b) [58].

(A)

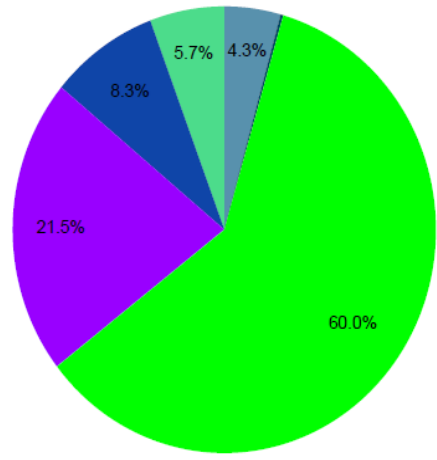

(B)

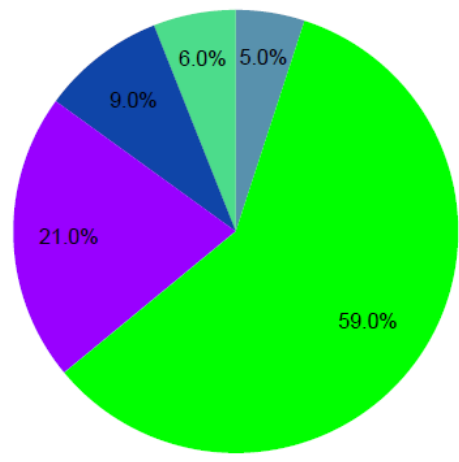

Fig. 13.2 Percentage of water resources for the desalination process for 2010 (a) and 2011 (b)

\section{CONCLUSION}

The desalination process is the most helpful technique in the areas which have plenty of seawater and brackish water as compared to less accessible freshwater. At present, there is the requirement of reducing the high cost involved in the installation of desalination plants. The most affected method to date is Reverse osmosis which accounts for $69 \%$ of freshwater production. There is a need of making use of renewable resources for desalination plants which can be eco friendly as well as less expensive. More attention is drawing by the hybrid system which results in better performance. Designing a Hybrid system mainly requires battery and energy storage devices which may be economically effective.

\section{REFERENCES}

[1] Wong KV, Pecora C. Recommendations for Energy-Water-Food Nexus Problems. Journal of Energy Resources Technology. 2015; 137(3):32002-7.

[2] Jimenez-Cisneros B. Responding to the challenges of water security: the Eighth Phase of the International Hydrological Programme, 2014-2021. Proceedings of the International Association of Hydrological Sciences. 2015; 366:10-19.

[3] Rijsberman FR. Water scarcity: Fact or fiction? Agricultural Water Management. 2006; 80(1-3):5-22.

[4] Micale G, Cipollina A, Rizzuti L. Seawater Desalination for Freshwater Production. Seawater Desalination: Conventional and Renewable Energy Processes. 2009; 1:1-15.

[5] Rao SM, Mamatha P. Water quality in sustainable water management. Current Science. 2004; 87(7):942-7.

[6] Buros, O. K., The ABC's of Desalting, International Desalination Association. Topsfield, Massachusetts. 1990. 
ICAASET-2021, 20-21 May, 2021, K.R. Mangalam University, Gurugram

International Journal of Technical Research \& Science (Special Issue) ISSN No.:2454-2024 (online)

[7] El-Dessouky, H.T., Ettouney, H. M., \& Al-Roumi, Y. (1999). Multi-stage flash desalination: present and future outlook. Chemical Engineering Journal, 73(2), 173-190.

[8] Hamed, O.A., Zamamiri, A. M., Aly, S., \& Lior, N. (1996). Thermal performance and exergy analysis of a thermal vapor compression desalination system. Energy conversion and management, 37(4), 379-387.

[9] El-Mudir, W., El-Bousiffi, M., \& Al-Hengari, S. (2004). Performance evaluation of a small size TVC desalination plant. Desalination, 165, 269-279.

[10] Shen, S., Zhou, S., Yang, Y., Yang, L., \& Liu, X. (2011). Study of steam parameters on the performance of a TVC-MED desalination plant. Desalination and water treatment, 33(1-3), 300-308.

[11] DeveshSingh, Freddie L. Inambo, International journal of Mechanical Engineering and Technology, Vol.10, August 2019, pp.244-270.

[12] YazanTaamneh, Madhar, M. Taamneh, Desalination, Vol. 291 (2002) 65-68.

[13] Qian Chen, Raid Alrowais, Muhammad Burhan, DoskhanYbyraiymkul, Muhammad Wakil Shahzad, Yong hi, Kim Choon Ng, Energy, Volume 205, August 2020.

[14] Al-Karaghouli, A., Renne, D., \&Kazmerski, L. L. (2009). Solar and wind opportunities for water desalination in the Arab regions. Renewable and Sustainable Energy Reviews, 13(9), 2397-2407.

[15] El-Bialy, E., Shalaby, S. M., Kabeel, A. E., \& Fathy, A.M. (2016). Cost analysis for several solar desalination systems. Desalination, 384, 12-30.

[16] Arjunan, T.V., Aybar, H.Ş., \& Nedunchezhian, N. (2009). Status of solar desalination in India. Renewable and Sustainable Energy Reviews, 13(9), 2408-2418.

[17] Pugsley, A., Zacharopoulos, A., Mondol, J.D., \& Smyth, M. (2016). Global applicability of solar desalination. Renewable energy, 88, 200-219.

[18] Abdulgader HA, Kochkodan V, Hilal N (2013) Hybrid ion exchange- pressure driven membrane processes in water treatment: a review.

[19] Alharati A, Swesi Y, Fiaty K, Charcosset C (2017) Boron removal in water using a hybrid membrane process of ion exchange resin and microfiltration without continuous resin addition. J Water Process Eng 17:32-39.

[20] Miyoshi T, Takahashi Y, Suzuki T, Nitisoravut R, Polprasert C (2018) Treatment of highly-colored surface water by a hybrid microfltration membrane system incorporating ion-exchange. Water SciTechnol Water Supply.

[21] Tanaka, Y. (2012). Ion-exchange membrane electrodialysis program and its application to multi-stage continuous saline water desalination. Desalination, 301, 10-25.

[22] Li, H., \& Zou, L. (2011). Ion-exchange membrane capacitive deionization: A new strategy for brackish water desalination. Desalination, 275(1-3), 62-66.

[23] Jacob, C. (2007). Seawater desalination: boron removal by ion exchange technology. Desalination, 205(13), 47-52.

[24] Galama, A.H., Saakes, M., Bruning, H., Rijnaarts, H.H.M., \& Post, J. W. (2014). Seawater predesalination with electrodialysis. Desalination, 342, 61-69.

[25] Krishnaveni Venugopal, Sangeetha Dharmalingam, Desalination and Water Treatment, 54 (2015) 285-294.

[26] Sadrzadeh, M., \& Mohammadi, T. (2008). Sea water desalination using electrodialysis. Desalination, 221(1-3), 440-447.

[27] Sosa-Fernandez, P.A., Post, J.W., Bruning, H., Leermakers, F.A.M., \& Rijnaarts, H.H.M. (2018). Electrodialysis-based desalination and reuse of sea and brackish polymer-flooding produced water. Desalination, 447, 120-132.

[28] Strathmann, H. (2004, December). Assessment of electrodialysis water desalination process costs. In Proceedings of the International Conference on Desalination Costing, Limassol, Cyprus (pp. 32-54).

[29] Chandrakala BJ, Vasudha DR, Mohammed Yason, Aravinda H.B, IJSART - Vol 3, Issue 6 - June 2017.

[30] Amir Naveed, Noor-ul-Amin, Fazli Saeed, M-Khraisheh, Mustafa Al Bakri, Saeed Gul, Desalination and Water Treatment, Vol-161 (2019), pp. 126-131

[31] Jun Cong Ge, Sam Ki Yoon and Nag Jung Choi, Appl. Sci. Vol. 8, (2018) 1-24.

[32] ThuyChih Nguyen, Trang Do Mai Tran, Van Bay dao, Quoc-TrungVu, HoangThai, March 2020.

[33] Polat, H., Vengosh, A., Pankratov, I., \& Polat, M. (2004). A new methodology for removal of boron from water by coal and fly ash. Desalination, 164(2), 173-188.

[34] Ali Boubakri, Amor Hafiane, Salah Al TaharBouguecha, Arabian Journal of Chemistry (2014)

[35] L. Donato, A. Garofalo, E. Drioli, O. Alharbi, S.A. Aljilil, A. Giscuoli, C. Algieri, Separation and Purification Technology, Volume 237, April 2020

[36] Atia E. Khalifa, Dahiru Lawal, M.A. Antar, 2014, International Mechanical engineering Congress and Exposition. [37] Li, J.M., Xu, Z.K., Liu, Z.M., Yuan, W.F., Xiang, H., Wang, S.Y., \& XU, Y.Y. (2003). Microporous polypropylene and polyethylene hollow fiber membranes. Part 3. Experimental studies on membrane distillation for desalination. Desalination, 155(2), 153-156.

[37] Pangarkar, B.L., \& Sane, M.G. (2011). Performance of air gap membrane distillation for desalination of ground water and seawater. World Academy of Science, Engineering, and Technology, 75, 177-181.

[38] Summers, E.K., \& Arafat, H.A. (2012). Energy efficiency comparison of single-stage membrane distillation (MD) desalination cycles in different configurations. Desalination, 290, 54-66.

[39] Mona A. Abdel-Fatah, Ain Shams Engineering Journal (2018).

[40] Natalia Garcia Domenech, Finn Purcell-Milton, Yurii K. Ginko, Materials today communication, Vol.23, June 2020, 100888. 
ICAASET-2021, 20-21 May, 2021, K.R. Mangalam University, Gurugram

International Journal of Technical Research \& Science (Special Issue) ISSN No.:2454-2024 (online)

[41] Altaee, A., Zaragoza, G., \& Van Tonningen, H.R. (2014). Comparison between forward osmosis-reverse osmosis and reverse osmosis processes for seawater desalination. Desalination, 336, 50-57.

[42] T. Younos and K.E. Tulou, "Overview of desalination techniques," Journal of Contemporary Water Research and Education, Vol. 132, no. 3, p. 10, 2005.

[43] E. Mathioulakis, V. Belessiotis, and E. Delyannis, "Desalination by using alternative energy: review and state-of-the-art," Desalination, vol. 203, no. 1-3, pp. 346-365, 2007.

[44] L.F. Greenlee, D.F. Lawler, B.D. Freeman, B. Marrot, and P. Moulin, "Reverse osmosis desalination: water sources, technology, and today's challenges," Water Research, Vol. 43, no. 9, pp. 2317-2348, 2009

[45] F. Macedonio and E. Drioli, "Pressure-driven membrane operations and membrane distillation technology integration for water purification," Desalination, vol. 223, no. 1-3, pp. 396-409, 2008.

[46] J.P. Mericq, S. Laborie, and C. Cabassud, "Vacuum membrane distillation for an integrated seawater desalination process," Desalination and Water Treatment, Vol. 9, pp. 293-302, 2009.

[47] Wang, P.; Chung, T.-S. Recent advances in membrane distillation processes: Membrane development, configuration design and application exploring. J. Membr. Sci. 2015, 474, 39-56.

[48] Suwaileh, W.A.; Johnson, D.J.; Sarp, S.; Hilal, N. Advances in forward osmosis membranes: Altering the sub-layer structure via recent fabrication and chemical modification approaches. Desalination 2018, 436, 176-201.

[49] Shen, L.-C.; Hankins, N.P. Forward Osmosis for Sustainable Water Treatment; Elsevier: Amsterdam, The Netherlands, 2016; pp. 55-76.

[50] Shaffer, D.L.; Werber, J.R.; Jaramillo, H.; Lin, S.; Elimelech, M. Forward osmosis: Where are we now? Desalination 2015, 356, 271-284.

[51] Wang, Y.N.; Goh, K.; Li, X.; Setiawan, L.; Wang, R. Membranes and processes for forward osmosis-based desalination: Recent advances and future prospects. Desalination 2018, 434, 81-99.

[52] Wang, P.; Chung, T.-S. Recent advances in membrane distillation processes: Membrane development, configuration design and application exploring. J. Membr. Sci. 2015, 474, 39-56.

[53] Altaee, A., Zaragoza, G., \& Van Tonningen, H.R. (2014). Comparison between forward osmosis-reverse osmosis and reverse osmosis processes for seawater desalination. Desalination, 336, 50-57.

[54] Taniguchi, M., Kurihara, M., \& Kimura, S. (2001). Boron reduction performance of reverse osmosis seawater desalination process. Journal of Membrane Science, 183(2), 259-267.

[55] Misdan, N., Lau, W. J., \& Ismail, A.F. (2012). Seawater Reverse Osmosis (SWRO) desalination by thinfilm composite membrane - Current development, challenges and future prospects. Desalination, 287, 228-237.

[56] Latteman S (2010) Development of an environmental impact assessment and decision support system for seawater desalination plants. CRC Press, Boca Raton.

[57] Abrams RH (2018) Legal control of water resources cases and materials. West Academic, New York.

[58] Reif JH, Alhalabi W (2015) Solar-thermal powered desalination: its significant challenges and potential. Renew Sustain Energy Rev 48:152-165. 